\title{
Let's swap: Early understanding of social exchange by British and Nepali children
}

\author{
PAUL L. HARRIS, MARÍA NÚÑEZ, and CAROLINE BRETT \\ University of Oxford, Oxford, England
}

\begin{abstract}
Recent research with adults has suggested that they readily understand conditional rules that include a deontic or prescriptive element. The possibility that young children might also understand such conditional rules when they are embedded in the context of an exchange agreement was explored in three studies. Children 3-7 years of age listened to stories in which two protagonists agreed to an exchange of mutual benefit. Children tested both in Britain and Nepal were accurate in identifying (1) when either protagonist had reneged on the agreement and (2) when both protagonists had kept the agreement. The findings indicate that young children are sensitive to the obligations that stem from an exchange agreement even if it is made between equals rather than imposed by adult authority.
\end{abstract}

Susan Isaacs recorded the following incident at the Malting House School when Dan (3 years 9 months) who had asked to play with a toy airship belonging to Frank (5 years 4 months), met with a refusal: "Presently Dan went to Frank and said, 'Frank, I have a big motor bus, and you can use that.' Frank said, 'Have you? Can I?' Dan said, 'Yes, and now will you let me use your airship?' Frank let him.” (Isaacs, 1933, p. 97). A similar bargain was struck some 2 months later, this time between Harold (5 years 3 months) and Dan (now 3 years 11 months). Harold asked Dan "to give him the large wooden motor bus 'for keeps,' and said, 'If you do, I'll give you my motor bus.' There was a long talk about this exchange and Dan agreed to it." (Isaacs, 1933, p. 100).

These two episodes are interesting for two reasons. First, it is the children themselves who proposed the exchange-no adult authority suggested or imposed it. Second, although the children reached the agreement for self-interested reasons (i.e., to obtain a desirable toy in the possession of another child), it is possible that they realized that the agreement, once accepted, imposed an obligation on them to hand over a toy themselves. Certainly, in each case, the agreed exchange went ahead. In the present paper, we examine more systematically whether or not young children understand the nature of such bargains. In particular, we ask whether they judge that someone who does not stick to an agreement to exchange goods is doing something wrong, even if no adult authority imposed the agreement.

Previous research has suggested that young children may have a special sensitivity to the norm of reciprocity,

This research was supported by funds from the Economic and Social Research Council, U.K. (R000 22 1174), and the Spanish Ministry of Education (Ex95 3442629). Correspondence should be addressed to P. L. Harris, Harvard University, Graduate School of Education, Larsen Hall, Appian Way, Cambridge, MA 02138 (e-mail: paul_harris@ harvard.edu). which is a key component of such exchange agreements. Levitt, Weber, Clark, and McDonnell (1985) observed that preschool children (29-36 months) were more willing to share a toy with a child who had previously shared with them. In addition, Berndt (1977) found that 6-year-olds judged the reciprocation of a favor to be less worthy of exceptional praise than spontaneous helping. By implication, they thought the reciprocation of a favor to be unexceptional, and even obligatory. In line with this latter interpretation, De Cooke (1992) found that 6-year-olds judged that it was important for someone who had been given help to return the favor. Indeed, they judged reciprocity on the part of the recipient to be important even when the help had been provided at minimal cost to the donor.

However, these findings all pertain to cases in which one protagonist has already received help or goods from another and, as a result, is placed in a position to reciprocate, or not. The naturally occurring episodes described by Isaacs (1933) differ from such cases in two ways. First, even before any actual transfer has taken place, there is an implication that it should be reciprocal. For example, when Dan offers the big motor bus, it is with the implication that the airship be received in exchange. Accordingly, in the context of these exchanges, reciprocity is not an obligation that suddenly or unexpectedly arises consequent on a transfer. Rather, reciprocity is negotiated and agreed ahead of any transfer. Second, given that an exchange has been agreed on, there is a possibility that either party can cheat or renege on the proposed agreement.

Recent research suggests that adults are very adroit at assessing the obligations entailed by deontic or prescriptive rules and the conditions under which the violation of such a rule has occurred (Cheng \& Holyoak, 1985; Cosmides, 1989). Suppose, for example, that there is a rule specifying that a traveler may enter the country only if he or she has been inoculated against cholera. Such a conditional rule can be violated by travelers who seek to enter 
the country without the relevant inoculation. When adults are told about such rules, including those that are entirely novel to them, they are very accurate in seeking out cases of potential violation (Cheng \& Holyoak, 1985; Cosmides \& Tooby, 1992). By contrast, adults are notoriously poor at seeking out cases that violate conditional, descriptive rules (e.g., if a card has a vowel on one side, then it has an even number on the other side; Wason, 1966). Hence, their accuracy in identifying violations of conditional rules involving a prescription (e.g., if a person enters the country, then he or she must be inoculated against cholera) has led to considerable interest and discussion. In particular, it has been proposed that human beings might enjoy some natural facility in reasoning about the implications of prescriptive or deontic rules. This proposal is consistent with the claim that human societies are organized around a considerable variety of such rules and with the related claim that our evolution as a social species might have favored the ability to detect "cheating"- cases in which a party to a given rule attempts to take a benefit without meeting the specified conditions (Cosmides \& Tooby, 1992; Cummins, 1996a, 1998).

Guided by the findings with adults, recent research with young children has uncovered a hitherto neglected facility in understanding the implications of conditional, prescriptive rules. Thus, Harris and Núñez (1996) found that 3 - and 4-year-old children are quite accurate at picking out cases in which an agent has obtained a benefit by engaging in a desirable activity but has not fulfilled the agreed condition for obtaining that benefit. For example, when told a story about a protagonist who must wear a helmet if she rides her bicycle, 3- and 4-year-olds readily identify the protagonist as naughty if she is depicted as riding her bicycle with no helmet. On the other hand, they do not judge as naughty cases in which the desired action is not being taken (e.g., the protagonist is walking, either with or without a helmet) or cases in which the desired action is being taken but the condition has been fulfilled (e.g., the protagonist is riding a bicycle but wearing her helmet). In addition, Núñez and Harris (1998a) showed that 3-and 4-year-olds distinguish between an accidental breach and a deliberate breach. Thus, pursuing the above example, they judge that it is naughty to ride a bicycle and deliberately remove one's helmet, but it is not naughty to ride a bicycle and accidentally lose one's helmet. Finally, two further studies demonstrate that preschool children are able not only to identify actual violations of deontic rules but also to check for potential violation. Using a reduced array version of the Wason task, Cummins (1996b) found that 3- and 4-year-old children accurately choose the relevant cases to inspect to check for a potential violation. Moreover, even when a full array version of the Wason task is used, 5-year-old children are accurate in seeking out violations (Núñez \& Harris, 1998b). Taken together, these studies show that young children are able to both recognize and seek out cases in which a protagonist engages in some desirable action, while deliberately flouting a specified condition.
However, an important limitation of the developmental findings gathered so far is that they involve an obligation unilaterally imposed by one person on another personnotably, an external authority, such as a parent on a child. Yet an important implication of the theory proposed by Cosmides and Tooby (1992) is that human beings recognize the implications of bilateral agreements spontaneously made between peers. Thus, they should recognize that each party to the agreement may cheat-and that each party is obligated not to cheat even if the agreement has been freely entered into by peers rather than imposed by an authority figure on a subordinate. In support of this expectation, several studies have shown that adults can readily switch between perspectives. More specifically, having been told about an agreement between two parties $\mathrm{A}$ and $\mathrm{B}$, adults accurately identify cases in which $\mathrm{A}$ is the cheater and B is the victim, as well as cases in which B is the cheater and A is the victim (Gigerenzer \& Hug, 1992; Holyoak \& Cheng, 1995; Manktelow \& Over, 1991; Politzer \& Nguyen-Xuan, 1992). However, there has been no investigation of when the understanding of such bilateral agreements emerges in development. We report three experiments in which children's understanding of a very simple bilateral agreement between two children was studied-namely, an agreement to exchange or swap goods. The two episodes described by Isaacs (1933) suggest that young children do enter into such agreements. We asked whether young children appreciate that, once an exchange agreement has been made, it imposes an obligation on each party and that either party can, in principle, cheat by not offering a benefit even though they take one.

\section{EXPERIMENT 1}

\section{Method}

Participants. We tested 32 preschool children, equally divided into two groups of 16 participants: 3 -year-olds ( 10 girls, 6 boys; age range, 39-46 months; $M=43$ months), and 4-year-olds (9 girls, 7 boys; age range, $48-60$ months; $M=55$ months). The children were recruited from three preschools in the city of Oxford, U.K. They came from families ranging from lower to middle class in terms of socioeconomic status.

Procedure. After a warm-up period in which the female experimenter talked to the children individually, they were given four test stories. Each story involved a different boy and girl and a different pair of items. The experimenter introduced the stories as follows: "I am going to tell you some stories about different children. Here's the first story." She then went on to tell the first story, pointing as she did so to the relevant part of a picture showing two children each holding an item. For example, one story was as follows:

This is a story about Susan and Simon. Look-Susan has a green brick to play with and Simon has a gray brick to play with. They say that they'll do a swap. Susan says that she'll let Simon play with her brick if Simon let's her play with his. And Simon says that he'll let Susan play with his brick if Susan let's him play with hers.

The picture accompanying this story depicted a girl holding a green brick and a boy holding a gray brick.

Having completed the story, the experimenter removed the picture that had accompanied the story and laid out four pictures that had been previously shuffled into a new random order. For each story, the four pictures depicted both protagonists in the exchange, 
Table 1

Mean Number of Choices (Maximum = 2) of Each of Four Picture Options as a Function of Age and Type of Question in Experiment 1 (Mean Correct Choice is Underlined)

\begin{tabular}{lcccc}
\hline & \multicolumn{4}{c}{ Picture Options } \\
\cline { 2 - 5 } Choice & No Swap & Girl Has Both & Boy Has Both & Swap \\
\hline Girl naughty? & 0.06 & 3-Year-Olds & \\
Boy naughty? & 0.13 & $\underline{1.63}$ & 0.19 & 0.13 \\
& & 4-Year-Olds & $\underline{1.50}$ & 0.13 \\
Girl naughty? & 0.13 & $\underline{1.75}$ & 0.06 & 0.06 \\
Boy naughty? & 0.06 & 0.00 & $\underline{1.88}$ & 0.06 \\
\hline
\end{tabular}

with one picture showing each of the following four cases: (1) both children still holding their original item; (2) the girl in possession of both items; (3) the boy in possession of both items; (4) each child holding the other's original item. The experimenter introduced these four pictures by saying, "Let's see what's happened in these pictures," and then drew attention to each picture in succession by saying, "Look at this picture ...," and describing its key elements. Thus, for the above story, the pictures were described as follows: "They each have a brick" for picture (1); "Susan has both bricks" for picture (2); "Simon has both bricks" for picture (3); and "They each have a brick" for picture (4).

The children were then asked to identify the picture in which either the boy or the girl protagonist had been naughty. For example, they might be asked, "Can you show me the picture where Susan has been naughty and hasn't done what she said?" Before making their picture choice, the children were briefly reminded of the relevant agreement-for example, "Remember she said that she'll let Simon play with her brick if Simon let's her play with his." When the children had chosen one of the four available pictures, they were given no feedback, but they were asked to explain their choice. Thus, pursuing the above example, they might be asked, "What is Susan doing in that picture which is naughty?"

The remaining three stories were similar in format but differed with respect to the names and appearance of the boy and girl involved and the items in their possession. Each child was tested on all four stories, order of presentation being randomly varied across children. On two stories, they were asked to say which picture showed the girl protagonist being naughty; on two stories, they were asked to say which picture showed the boy protagonist being naughty. Half the children in each group were questioned about the girl protagonist for stories A and B, and half were questioned about the boy protagonist for stories $\mathrm{C}$ and $\mathrm{D}$. The remaining children were questioned in the reverse fashion.

\section{Results}

The children's responses were scored using both a lenient and a stringent criterion. For the lenient criterion, the children were scored for the number of stories in which they chose the correct picture when questioned about the girl and boy protagonists. For the stringent criterion, the children were scored for the number of stories in which they (1) chose the correct picture and (2) backed it up with an appropriate justification by referring either to an action by the relevant protagonist inconsistent with the agreed exchange (e.g., "He's not sharing them" or "She stealed his felt-tip") or to the number of items in his or her possession (e.g., "He's got both of the balls" or "She's got $t w o ")$. The requirement that a choice response should be accompanied by an appropriate verbal justification can sometimes lead to an underestimate of young children's competence. Accordingly, we report results for the lenient criterion only. It should be noted, however, that the children performed well across the four stories even using the stringent criterion (3-year-olds, $M=3.13, S D=1.31$; 4year-olds, $M=3.58, S D=0.81$ ).

Table 1 shows the mean number of choices directed at the correct picture (and each of the incorrect pictures) as a function of age and type of question. Means for the correct picture (maximum $=2.00$ ) are underlined. Inspection of Table 1 shows that the children mainly selected the correct picture from the four available pictures, irrespective of age and type of question. When asked to say where the girl was being naughty, they mainly pointed to the picture showing the girl in possession of both items; when asked to say where the boy was being naughty, they mainly pointed to the picture showing the boy in possession of both items. A $2 \times 2$ analysis of variance of age $\times$ type of question was performed on the mean number of correct choices. As might be expected from the consistently good performance evident in Table 1, there were no significant effects. (Here, and throughout, the alpha level was set at .05.) Separate $t$ tests for each age group confirmed that the mean overall performance of both 3-year-olds $(M=$ $3.13)$ and 4-year-olds $(M=3.63)$ exceeded the expected chance value of 1.0 [3-year-olds, $t(15)=6.49, S E=0.328$; 4-year-olds, $t(15)=13.02, S E=0.202]$.

\section{Discussion}

The results of Experiment 1 showed that the children in both age groups were quite accurate in identifying cases in which either the female protagonist or the male protagonist had broken the agreement to swap. The children typically picked out the picture showing the wrongdoer in possession of both items. In addition, they frequently backed up that choice by saying that the wrongdoer had engaged in an action that violated the exchange agreement (e.g., taking the other's item, not handing over their own item, or keeping both items). These findings provide persuasive evidence that preschool children understand the implications of a reciprocal agreement between two peers.

However, there are two issues to consider in assessing the depth of that understanding. First, it is possible to argue that, in making their picture choices and in offering justifications, the children made use of a shortcut or heuristic based on numerosity. More specifically, they may have surveyed the four pictures and, when asked to indicate where a particular protagonist was being naughty, looked for the picture showing the named protagonist in possession of two items. Using this heuristic, they could have made a correct choice of picture and backed it up by referring to the number of items possessed by the designated character. Recall that the children's justifications did often refer to the protagonist having two or both items.

There are two arguments against this interpretation. First, the children often justified their picture choice by referring to the protagonist's nonreciprocal action of tak- 
Table 2

Mean Number of Choices (Maximum = 4) of Each of Four Picture Options in Experiment 2 (Mean Correct Choice is Underlined)

\begin{tabular}{cccc}
\hline \multicolumn{4}{c}{ Picture Options } \\
\cline { 2 - 4 } No Swap & Girl Has Both & Boy Has Both & Swap \\
\hline 0.75 & 0.62 & 0.18 & $\underline{2.50}$ \\
\hline
\end{tabular}

ing or not sharing. Such justifications suggest that the children realized what actions had produced the inequality and were not simply concerned with the final numerosity. Second, 5 younger children and 3 older children offered at least one justification in which they referred within the same justification to both the action and the ensuing inequality (e.g., "She's got two-won't give it him back" or "She took both of them"). A plausible implication of such justifications is that, when the children referred only to the final numerosity, they understood how that inequality had been brought about, even if they did not make it explicit. Despite these counterarguments, Experiment 2 was designed to rule out the use of a shortcut based on numerosity.

The second consideration in weighing the findings of Experiment 1 is that, even if the children did not make use of a shortcut, their pattern of responding shows only that they understood that each party to an agreement could renege on what was agreed. It provides no direct evidence that the children also understood what constituted a fulfillment of the agreement for both parties.

Experiment 2 was designed to address these two concerns. The children were presented with a task in which they had to identify the picture showing completion of the agreement. This meant that the shortcut of choosing the protagonist in possession of a given number of items would not yield the right answer. Specifically, the children were asked to pick out the picture in which both parties had honored the agreement by being "good." If the children attempted a shortcut solution based on numerosityfor example, looking for a picture in which each protagonist was in possession of one item-they would fail to distinguish between the picture showing the original disposition of the items and the picture showing the swap having taken place.

Given that both age groups in Experiment 1 had performed very accurately, only 3 -year-olds were tested in Experiment 2.

\section{EXPERIMENT 2}

\section{Method}

Participants. We tested 16 preschool children (10 girls, 6 boys; age range, 36-47 months; $M=3$ years 6 months). The children were recruited from two preschools in the city of Oxford. They came from families ranging from lower to middle class in terms of socioeconomic status.

Procedure. The children were tested in the same way as in Experiment 1 using the same four stories. Each child was tested on all four stories, order of presentation being randomly varied across children. However, instead of being asked to indicate the picture where either the male or the female was being naughty, the children were asked to indicate the picture where the protagonists were being good. Thus, once the four pictures had been laid out and described, the experimenter asked, "Can you show me the picture where they have both been good and done what they said? Remember they said they would do a swap." Once the children had made their choice, they were asked to provide a justification as follows: "What are they doing in that picture which is good?"

\section{Results}

As in Experiment 1, the children's responses were scored using both a lenient and a stringent criterion. For the lenient criterion, the children were scored for the number of stories in which they chose the correct picture. For the stringent criterion, the children were scored for the number of stories in which they (1) chose the correct picture and (2) backed it up with an appropriate justification by referring either to actions that completed the exchange (e.g., "They've changed the sweets" or "They've swapped") or to the possession of an item by each character (e.g., "They've got one each" or "Both got a brick each"). The children performed quite well even using the stringent criterion $(M=2.36, S D=1.45)$. However, for the reason given above, we focus on the lenient criterion.

Table 2 shows the mean number of choices directed at the correct picture and each of the incorrect pictures. The mean for the correct picture is underlined (maximum = 4). Inspection of Table 2 shows that the children mainly selected the correct picture-namely, the picture that showed the exchange having taken place. A $t$ test confirmed that selection of the correct picture exceeded the expected chance value of $1.0[t(15)=4.24, S E=0.354]$.

\section{Discussion}

Experiment 2 provides further evidence of the early understanding of social exchanges agreements. The children's accurate performance in this experiment shows that it was unlikely that the children in Experiment 1 used a shortcut based on numerosity. Moreover, it shows that their understanding included an appreciation of what constitutes the fulfillment of such an agreement. This conclusion is reinforced by a consideration of the types of justifications that the children gave for their judgments. As Table 3 illustrates, each child produced at least one reference to the exchange of items by the two characters or to the possession of one item by each character.

Taken together, the findings of Experiments 1 and 2 indicate that young children can identify actions that would either fulfill or renege on an agreement to exchange goods. The children appropriately adjusted their choice of picture and the justification that they offered, depending on whether they were asked to pick out one of the protagonists being naughty, as in Experiment 1, or both protagonists being good, as in Experiment 2. The main goal of Experiment 3 was to examine the understanding of reciprocal exchange by non-Western children. 
Table 3

Illustrative Examples From Each Child's Justifications in Experiment 2
Child 1,36 months "They've swapped."
Child 2, 36 months "They've got one each."
Child 3, 38 months "Swapped them over."
Child 4, 39 months "They done a swap."
Child 5, 40 months "Swapping."
Child 6, 41 months "Both got a brick each."
Child 7, 42 months "Swapped."
Child 8,42 months "They've swapped."
Child 9, 42 months "They've changed the sweets."
Child 10, 43 months "Done a swap."
Child 11, 43 months "Said they were going to swap."
Child 12, 43 months "They've swapped round."
Child 13, 44 months "They've done a swap."
Child 14, 44 months "They've swapped."
Child 15, 45 months "They've got one each."
Child 16, 47 months "Swapped."

\section{EXPERIMENT 3}

Researchers who have developed and tested social exchange theory have routinely assumed that an understanding of social exchange is a universal form of social reasoning (Cosmides \& Tooby, 1992; Cummins, 1996a, 1998), likely to emerge at approximately the same period of development (Cosmides, 1985). However, developmental research on the understanding of such agreements has hitherto been confined to the study of young children growing up in Western, industrialized countries. A major goal of Experiment 3, therefore, was to discover whether young children growing up in a non-Western, traditional, preindustrial community would display the same pattern of judgment. Experiment 3 was carried out with children in Bhaktapur, a market town in Nepal. The children ranged from 3 to 7 years of age and varied in terms of the amount of schooling that they had received (from approximately 6 months to at least 2 years). Amount of schooling was not systematically related to age because the children began school at different ages. Hence, it was possible to examine the effects of age and schooling separately.

The test format of Experiment 3 combined elements from Experiments 1 and 2. More specifically, using the same presentation format, the children were presented with a total of six stories, and, for each of two stories, they were asked to say (1) where the male protagonist had been naughty, (2) where the female protagonist had been naughty, and (3) where both protagonists had been good. Accordingly, Experiment 3 constituted a more demanding test of children's understanding of an exchange agreement, in that, depending on the test question, the children were expected to focus on the violation of that agreement or on its completion.

A further modification of the procedure concerned the items involved in the exchange. In Experiments 1 and 2, each story concerned two items that came from the same category but differed in accidental features (e.g., a red pencil and a blue pencil). Arguably, it is more difficult to understand an agreement to exchange items from different categories, because each protagonist acts from a de- sire that is evidently distinct from, rather than equivalent to, the other party to the exchange. To assess this possibility, the children were given three stories involving an exchange of items from the same category and three stories involving an exchange of items from different categories.

\section{Method}

Participants. The children were tested in a small school serving children in the market town of Bhaktapur, Nepal. Parents ranged from low to middle socioeconomic status, with most parents involved in agricultural work, cottage industries, or shopkeeping in the town or surrounding villages. All children spoke Nepali, the main language of instruction in the school. The school followed local teaching practices, which depart from Western practices in several respects. There is a considerable emphasis on rote learning (i.e., children repeat and chant material en masse, children never work in small groups, and they rarely receive individual attention from the teacher).

We tested 54 children in the final sample. They were drawn from three different classes: nursery ( $n=17$; age range, $42-83$ months; $M=58$ months); junior kindergarten ( $n=17$; age range, 46-84 months; $M=64$ months); senior kindergarten ( $n=20$; age range, 62-85 months; $M=75$ months). Nursery children had received approximately 6 months of morning school only; junior kindergarten children had received 1 year of morning school and approximately 6 months of all-day school; and senior kindergarten children had received 1 year of morning school and approximately 18 months of all-day schooling.

Procedure. Testing took place in an unused classroom familiar to the children. A Nepali assistant, who knew the children, put them at ease. The experiment was conducted in Nepali by the assistant with one of the authors (C.B.) present to order the items, oversee the procedure, and write down the children's responses. Most participants were also familiar with C.B. because she had previously taught at the school.

All participants were tested on six different stories, each with the same format-namely, a girl and a boy who agreed to swap two items with each other. In three of the stories, the items came from the same basic category but differed in color (e.g., a red book and a blue book); in three of the stories, the items came from different categories (e.g., a pencil sharpener and an eraser). For each of two stories, the children were asked to say (1) where the male protagonist had been naughty, (2) where the female protagonist had been naughty, or (3) where both protagonists had been good. The order of stories was randomized across children.

After a short warm-up period, the participants were shown a picture of a boy and a girl. They were told that the same-sex child had the same name as themselves and were asked to suggest a name for the opposite-sex child. (This procedure proved effective in helping the children to remember the names of each protagonist.) Then, as in Experiment 1, the item belonging to each protagonist was indicated, and the children were told that the protagonists had agreed to a swap.

Once the four test pictures were laid out, the children were asked one of the three test questions, and, when they had chosen a picture, they were asked to say what the relevant character(s) was (were) doing in the picture that was naughty (good).

\section{Results}

As in Experiments 1 and 2, the children were scored using a lenient and a stringent criterion. We again focus on the lenient criterion-namely, correct picture choice. The mean number of choices (maximum $=2$ ) directed to each picture is shown in Table 4 as a function of schooling and type of question. Scores were collapsed across type of item (same vs. different) because this factor had 
Table 4

Mean Number of Choices (Maximum = 2) of Each of Four Picture Options as a Function of School Group and Type of Question in Experiment 3 (Mean Correct Choice is Underlined)

Picture Options

Choice No Swap Girl Has Both Boy Has Both Swap Nursery

\begin{tabular}{lllll} 
Girl naughty? & 0.24 & $\underline{0.71}$ & 0.59 & 0.47 \\
Boy naughty? & 0.35 & 0.59 & $\underline{0.59}$ & 0.47 \\
Both good? & 0.41 & 0.53 & 0.53 & $\underline{0.53}$ \\
& \multicolumn{5}{l}{ Junior Kindergarten } \\
Girl naughty? & 0.12 & $\underline{1.06}$ & 0.53 & 0.29 \\
Boy naughty? & 0.12 & 0.41 & $\underline{1.06}$ & 0.41 \\
Both good? & 0.18 & 0.47 & 0.65 & $\underline{0.71}$ \\
& \multicolumn{4}{l}{ Senior Kindergarten } \\
Girl naughty? & 0.00 & $\underline{1.60}$ & 0.25 & \\
Boy naughty? & 0.05 & 0.30 & $\underline{1.40}$ & 0.15 \\
Both good? & 0.45 & 0.10 & $\underline{0.30}$ & $\underline{1.15}$ \\
\hline
\end{tabular}

no effect on the children's choices. Means for the correct picture are underlined. Inspection of Table 4 shows that the mean number of correct choices made for each type of question increased with schooling. A $3 \times 3$ analysis of school group $\times$ question type with age in months as a covariate was performed on these data. There was a main effect of school group $\left[F(2,50)=11.83, M S_{\mathrm{e}}=0.61\right]$, with age partialed out. Three pairwise comparisons of the school groups all proved significant, confirming that the number of correct picture choices increased with schooling. Finally, the effect of question type almost reached significance $\left[F(2,100)=2.80, M S_{\mathrm{e}}=0.54, p=.066\right]$.

To check whether performance varied with age, the children were divided into three equal-sized age groups $(n s=18)$ and an analysis of age $\times$ type of question was performed with amount of schooling as a covariate (where amount of schooling was defined in terms of the number of months of half-day schooling, with double weight given to all-day schooling). There were no significant main effects and no interactions.

To assess whether the children in each school group could reliably assess cheating and compliance in relation to an exchange agreement, $t$ tests were conducted comparing the mean number of correct responses to chance performance for each of the nine combinations of school group and type of question. For the nursery group, performance was not above chance on any of the three questions; for the junior kindergarten group, performance was above chance on the two questions about naughtiness but not on the question about being good; for the senior kindergarten group, performance was above chance on all three questions.

\section{GENERAL DISCUSSION}

Experiment 3 offered a stringent assessment of children's understanding of exchange agreements. First, the children were asked not only to identify a protagonist who had reneged on the agreement but also to indicate where both protagonists had kept the agreement. Second, the combination of these questions meant that the children could not rely on the strategy of pointing to the picture showing the named protagonist in possession of a given number of items. Third, the children were asked about agreements to exchange items from different categories as well as from the same category. Considered as a group, the children adjusted their choice of picture appropriately, despite these various demands. This flexible pattern of responding shows that the children understood what it meant for either party to break the agreement and what it meant for both parties to keep it.

Despite this flexibility, performance was not uniformly good across the entire group of children. The children's accuracy in picking out the correct picture improved with schooling even when the potential contribution of age was partialed out. The nursery children performed at chance in answering all three questions, the junior kindergarten children performed above chance when asked about cheating, and the senior kindergarten children performed above chance when asked about cheating or compliance. This effect of schooling cannot be attributed to age-related changes in general cognitive ability across the three school groups. When the children were regrouped by age and the contribution of schooling was partialed out, no effect of age was observed.

Why did the children's performance vary with schooling? One possibility is that, when children are at school, they have the opportunity to encounter, and enter into, an increasing number of exchange agreements with other children. As a result of this experience, they acquire a generalized "schema" for exchange and become increasingly adroit at grasping the implications of any proposed bargain or swap. However, a plausible argument against this interpretation is that children in Nepal have many opportunities for interaction with other children-unsupervised by adults-whether or not they are in school. Indeed, because of the teaching system followed in the Nepali school, it is possible that children's opportunities for informal interaction with other children are reduced in various ways once they enter school; for example, the Nepali children were not given the opportunity to work in small groups during their daily schedule.

An alternative possibility is that schooling, particularly when it involves the more formal instruction in reading and arithmetic that is associated with kindergarten, introduces children to the type of demands that they must face during experimental testing: They must pay attention to an adult's extended discourse and link that discourse to a set of illustrative materials. On this second interpretation, the weak performance of the nursery children should be interpreted cautiously because it may only reflect their unfamiliarity with the testing format rather than any difficulty in understanding exchange agreements per se. The more accurate performance of the two kindergarten groups, on the other hand, together with the findings from Experiments 1 and 2, provides persuasive evidence of chil- 
dren's competence at understanding conditional exchange agreements between peers. Below, we consider in more detail the implications of that competence.

First, the findings provide further evidence that young children understand conditional rules that are embedded in a prescriptive or deontic context. This conclusion is in agreement with previous research showing that, although young children may not be accurate in identifying violations of conditional, descriptive rules, they are accurate in identifying violations of conditional, prescriptive rules (Cummins, 1996b; Harris \& Núñez, 1996). More generally, the pattern of results reinforces the conclusion that has emerged from research on adult reasoning-namely, that competence at reasoning is best analyzed not as a general ability that crosscuts various content areas but as a domain-specific skill.

Second, the findings show that children's sensitivity to conditional rules is not confined to rules imposed on them by an external authority, such as an adult. In the stories used in each of the present experiments, no adult was referred to, and the proposal to make an exchange came from the story protagonists themselves, in that it was voiced by each child who was party to the exchange. In earlier developmental studies of prescriptive rules, by contrast, the rule has been introduced by an authority figure. In some respects, the finding that children make deontic judgments independent of any external authority echoes a conclusion that has emerged from research on early moral development. Thus, both Turiel (1997) and Smetana (1993) have argued that young children do not always look to adult authority in the evaluation of a moral breach: They judge that certain actions may be right or wrong, no matter what judgment external authority imposes. However, both of these researchers have argued that, when children make such autonomous judgments, they are guided by an assessment of the objective benefit or harm that has accrued to the agents in question. Our findings show that children do not always use this form of assessment in making a deontic judgment. They also understand the way in which the parties to an agreement are bound by the terms of an agreement that they have entered into. In particular, Experiments 2 and 3 showed that young children understand that the parties should complete an agreed exchange. The children could not determine whether both protagonists had been good by simply noting their objective welfare-for example, by checking whether they were each in possession of an equivalent benefit. In that case, the children would have frequently chosen the picture depicting the original disposition of the items. Instead, the children needed to assess whether the exchange had taken place, as agreed.

As noted, children's successful performance would be expected on the basis of recent analyses of adults' facility at grasping the implications of deontic rules-particularly, social exchange agreements. It is worth noting, however, that analyses of adult competence have concentrated on the detection of cheating (Cosmides \& Tooby, 1992). Little attention has been given to the way that adults recog- nize when each party to the agreement has fulfilled their obligation. The results of Experiments 2 and 3 highlight the way that young children recognize the execution of an exchange.

In the light of this latter finding, we speculate that adult competence extends beyond the detection of cheating. From an evolutionary point of view, it is reasonable to postulate that human beings are attuned to two different social strategies by prospective partners: a cheating strategy in which the partner takes a benefit without reciprocating, and a cooperative strategy in which the partner takes a benefit but does reciprocate. Selection of future exchange partners could then be based on that categorization. In subsequent research, it will be interesting to explore this model in the context of development. It raises the possibility that children base their willingness to agree to an exchange with a given partner on their judgment about that partner's trustworthiness and, more specifically, on the likelihood that a partner will cheat versus reciprocate. Children might assess trustworthiness in various ways. They may be guided by their own prior experience as victim or beneficiary or, alternatively, by their knowledge of a partner's prior history as an exchange partner who cheats or reciprocates.

In conclusion, the results of the three experiments indicate the fruitfulness of combining the study of children's early understanding of obligation with recent findings regarding adults' reasoning about conditional rules. In the longer term, this enterprise will help us to assess how young children's early capacity for sharing and trading becomes incorporated into a wider understanding of the obligations imposed by mutual agreements.

\section{REFERENCES}

BERndT, T. J. (1977). The effect of reciprocity norms on moral judgement and causal attribution. Child Development, 48, 1322-1330.

Cheng, P. W., \& Holyoak, K. J. (1985). Pragmatic reasoning schemas. Cognitive Psychology, 17, 391-416.

Cosmides, L. (1985). Deduction or Darwinian algorithms? An explanation of the "elusive" content effect on the Wason selection task. Unpublished doctoral dissertation, Harvard University (University Microfilms 86-02206).

Cosmides, L. (1989). The logic of social exchange: Has natural selection shaped how humans reason? Studies with the Wason selection task. Cognition, 31, 187-276.

Cosmides, L., \& Toовy, J. (1992). Cognitive adaptations for social exchange. In J. H. Barkow, L. Cosmides, \& J. Tooby (Eds.), The adapted mind: Evolutionarypsychology and the generation of culture (pp. 163228). Oxford: Oxford University Press.

Cummins, D. D. (1996a). Evidence for the innateness of deontic reasoning. Mind \& Language, 11, 160-190.

Cummins, D. D. (1996b). Evidence of deontic reasoning among 3- and 4-year-old children. Memory \& Cognition, 24, 823-829.

Cummins, D. D. (1998). Social norms and other minds: The evolutionary roots of higher cognition. In D. D. Cummins \& C. A. Allen (Eds.), The evolution of mind (pp. 30-50). New York: Oxford University Press.

De Cooke, P. A. (1992). Children's understanding of indebtedness as a feature of reciprocal help exchanges between peers. Developmental Psychology, 28, 948-954.

Gigerenzer, G., \& Hug, K. (1992). Domain-specific reasoning: Social contracts, cheating, and perspective change. Cognition, 43, 127-171. 
Harris, P. L., \& NúÑEZ, M. (1996). Understanding of permission rules by pre-school children. Child Development, 67, 1572-1591.

HolyoAk, K., \& Cheng, P. W. (1995). Pragmatic reasoning with a point of view. Thinking \& Reasoning, 1, 289-312.

IsAACS, S. (1933). Social development in young children. London: Routledge.

Levitt, M. J., Weber, R. A., Clark, M. C., \& McDonnell, P. (1985). Reciprocity of exchange in toddler sharing behavior. Developmental Psychology, 21, 122-123.

Manktelow, K., \& Over, D. E. (1991). Social roles and utilities in reasoning with deontic conditionals. Cognition, 39, 85-105.

NúÑEZ, M., \& Harris, P. L. (1998a). Psychological and deontic concepts: Separate domains or intimate connection? Mind \& Language, 13, $153-170$

NúÑEZ, M., \& HARRIs, P. L. (1998b, July). Young children's reasoning about prescriptive rules: Spotting transgressions through the selection task. Paper presented at the XVth Biennial Meeting of the Inter- national Society for the Study of Behavioral Development, Berne, Switzerland.

Politzer, G., \& NGuyen-Xuan, A. (1992). Reasoning about promises and warnings: Darwinian algorithms, mental models, relevance judgements or pragmatic schemes. Quarterly Journal of Experimental Psychology, 44A, 402-421.

Smetana, J. G. (1993). Understanding of social rules. In M. Bennett (Ed.), The child as psychologist (pp. 111-141). London: Harvester Wheatsheaf.

TuriEL, E. (1997). The development of morality. In N. Eisenberg (Ed.), Handbook of child psychology: Vol. 3. Social, emotional and personality development (pp. 863-932). New York: Wiley.

WASON, P. C. (1966). Reasoning. In B. Foss (Ed.), New horizons in psychology (Vol. 1, pp. 135-151). Harmondsworth, U.K.: Penguin.

(Manuscript received September 11, 1998; revision accepted for publication March 3, 2001.) 